\title{
REFEREES FOR VOLUME 30
}

G. Allen, National Institute of Mental Health, Rockville, Maryland

J. Bayley-Wilson, Department of Biometry, Louisiana State University Medical Center, New Orleans C.E. Boklage, Department of Microbiology, East Carolina University, Greenville, North Carolina

G. Brencl, The Mendel Institute, Rome

R. Chakraborty, Center for Demographic and Population Genetics, University of Texas, Houston

J.C. Chrlstian, Department of Medical Genetics, Indiana University, Indianapolis

B. De Finettl, Institute of Probability Calculus, School of Sciences, University of Rome

R.C. Elston, Department of Biometry, Louisiana State University Medical Center, New Orleans

Z. Hrubec, Division of Medical Sciences, National Research Council, Washington, D.C.

J. Kaprio, Department of Public Health Science, University of Helsinki

F. Leroy, Department of Obstetrics and Gynecology, Free University of Brussels

I. MacGIlllvray, Department of Obstetrics and Gynecology, University of Aberdeen

N.G. Martln, Department of Population Biology, Australian National University, Canberra

W.E. Nance, Department of Human Genetics, Medical College of Virginia, Richmond

L.W. Pickle, Environmental Epidemiology Branch, N.C.I., National Institute of Health, Bethesda, Maryland

S. Selvin, Department of Biomedical and Environmental Health Sciences, University of California, Berkeley

B.K. Suarez, Department of Psychiatry, Washington University in St. Louis, Missouri

R.S. Wilson, Child Development Unit, Health Sciences Center, University of Louisville, Kentucky 